\title{
Identification of Virulences of the Rust Fungus Melampsora larici-populina Occurring in Chile
}

Marta V. Albornoz, Centro Regional de Innovación Hortofrutícola de Valparaíso Ceres, Pontificia Universidad Católica de Valparaíso, Quillota, Chile; Mauricio Lolas, Laboratorio de Fitopatología, Facultad de Ciencias Agrarias, Universidad de Talca, Chile; and Jaime A. Verdugo and Claudio C. Ramírez, ${ }^{\dagger}$ Centre for Molecular and Functional Ecology, Instituto de Ciencias Biológicas, Universidad de Talca, Chile

\begin{abstract}
Melampsora larici-populina Kleb. is a Eurasian species that causes leaf rust of many species of Populus from sections Tacamahaca and Aigeiros. This rust has been inadvertently introduced to many parts around the world affecting poplar species that grow naturally, which may be susceptible to this fungus. In Chile, early European settlers introduced poplars; rust, attributed to $M$. larici-populina, has been reported in these trees since 1918. However, a modern confirmation has been lacking, and pathogenic variation of the Chilean population of M. larici-populina has not been investigated. Using a morphological analysis of urediniospores and sequencing of internal transcribed spacer (ITS) regions, we confirmed the

presence of M. larici-populina in Chile. ITS regions exhibited $100 \%$ homology with $M$. larici-populina. Scanning electron microscopy showed that spores were 26 to $47 \mu \mathrm{m}$ in length, 13 to $16 \mu \mathrm{m}$ in width, and echinulate except for apices, which are smooth, characteristics described for this species of rust. The variability of M. larici-populina is characterized by the presence of pathotypes, which allows the fungus to infect despite the resistance of certain poplar hybrids. We concluded that the identified spores belong to M. larici-populina, with virulences 1, 2, 3, 4, 5, and 6 . These results describe variation in virulence of $M$. larici-populina, which suggests the presence of a sexual stage in Chile.
\end{abstract}

Poplar leaf rust is one of the most important diseases of poplar species worldwide. The disease is caused by species of Melampsora (Frey et al. 2005), such as M. medusae, M. allii-populina, and M. laricipopulina. These organisms induce the premature loss of poplar foliage, decreasing vigor of individual trees on affected plantations (Frey et al. 2005). Species of Melampsora are obligate parasites, and their telial hosts are Populus spp. of the Aigeiros and Tacamahaca sections (Pinon 1992). The disease is distributed throughout North America, South America, Asia, Europe, and Oceania. M. laricipopulina was described in Europe in 1902 by Dr. H. Klebahn (Vialle et al. 2011). In North America, Newcombe and Chastagner reported this rust in 1993. Other reports of M. larici-populina in South America are described in Argentina (Fresa 1936) and Colombia (Kern and Thurston 1954). The presence of M. larici-populina in Chile has been reported in the literature (Zamudio et al. 2012), although this finding has not been verified. Specifically, Spegazzini (1918) described its presence only by visual inspection this fungus, and Mujica et al. (1980) make mention of Spegazzini when describing rust in Chile without any further morphological evidence. Dowkiw et al. (2003) mention that $M$. larici-populina was detected in Chile but only cite a personal communication of J. Pinon. Rubio-Meléndez et al. (2011) showed the susceptibility of poplar hybrids to Melampsora spp. in Chile, although not the identification of Melampsora.

The genus Melampsora is a heteroecious, macrocyclic rust typically manifesting in five stages (Barrès et al. 2008): basidia producing in the basidiospores (0), spermagonia producing the spermatia (S), aeciospores born within the aecia (I), urediniospores in the uredinia (II), and teliospores in the telia (III). In the case of M. laricipopulina, urediniospores and teliospores are observed on poplars, whereas aeciospores and pycniospores develop on the telial host Larix spp., Pinus ponderosa, $P$. contorta, and $P$. radiata (Hacquard et al. 2011; Newcombe and Chastagner 1993; Newcombe et al. 1994). However, in some climates, stages I and III are not necessary

${ }^{\dagger}$ Corresponding author: Claudio C. Ramírez; E-mail: clramirez@utalca.cl

Funding: Funding was provided by Universidad de Talca.

Accepted for publication 14 May 2018.

(c) 2018 The American Phytopathological Society to perpetuate the species, and these stages can be replaced by an extended stage II (Barrès et al. 2012). This finding has been observed in Chile, where the fungus maintains the capacity to develop without an alternate host, displaying only the asexual phase. The development of the life cycle is typically initiated when the urediniospores remaining in the buds have fallen with the leaves during autumn/winter, infecting new leaves in the spring (Hacquard et al. 2011).

The variability of $M$. larici-populina populations is characterized by the presence of pathotypes, which in this case are interspecific variants distinguishable by their virulences on poplar hybrids. Pathogen variability is of great importance in Europe and North America because resistant hybrids with qualitative resistances have been overcome by new pathotypes of the fungus.

M. larici-populina developed pathotypes that infect some resistant poplar hybrids worldwide (Pinon and Frey 1997; Steenackers et al. 1994). European studies have described eight pathotypes of M. laricipopulina, which can be discriminated by using the leaf disk technique on resistant poplar hybrids (Pinon and Frey 2005; Pinon and Lefèvre 1994). Additionally, the urediniospore can be morphologically identified by using scanning microscopy (Spiers and Hopcroft 1985). Identification can be complemented by using molecular techniques such as random amplification of polymorphic DNA polymerase chain reaction (PCR), amplified fragment length polymorphism, microsatellites, and sequencing of the internal transcribed spacer (ITS) region (Cervera et al. 1996; Gérard et al. 2006; Husson et al. 2013; Steimel et al. 2005; Xhaard et al. 2009).

The aims of this study were to (i) verify the presence of $M$. laricipopulina in Chile using morphological and molecular approaches and (ii) determine the virulence diversity of this pathogen in some areas within the country. The results are particularly important for programs of poplar protection and breeding.

\section{Materials and Methods}

Collecting and multiplying rust strains. Poplar leaf rust samples were collected from hybrids belonging to crosses $P$. trichocarpa $\times$ $P$. deltoides, $P$. deltoides $\times P$. nigra, $P$. trichocarpa $\times P$. nigra, and from $P$. nigra. Samples were collected from several locations in central and south Chile (approximately $800 \mathrm{~km}$ apart). Sites of collection were poplar stands from several regions of central and south Chile. These stands were experimental nurseries established in lands of several small private companies taking part in a long-term collaboration with the Center of Poplar Research of University of Talca. These 
stands were in the following locations: Coinco (O'Higgins Region), Talca and Parral (Del Maule Region), Cabrero, Yumbel, and Los Ángeles (Biobio Region), Temuco and Traiguén (Araucanía Region), and Valdivia (Los Ríos Region) (the exact geographic location and the number of samples per site are indicated in Table 1).

Morphological characterization of leaf rust was performed on infected leaves, which were analyzed in the laboratory using optical and electron microscopy to identify the rust species. Pathotypes in Chile were detected by inoculating differential poplar clones. Additionally, molecular characterization by sequencing the ITS1 region of DNA using the primer pair ITS1 and ITS4 was performed. Some infected leaves were obtained from poplar trees growing naturally or on private plantations. A total of 229 samples of poplar leaf rust spores were collected, isolated, and inoculated onto leaves of Populus $\times$ euroamericana 'Robusta', because this cultivar has shown to be susceptible to all virulences of the fungus (Pinon and Frey 2005). These leaves were transferred to a growth chamber under controlled conditions $\left(18 \pm 2^{\circ} \mathrm{C}\right.$ and photoperiod of $16 \mathrm{~h} \mathrm{light} / 8 \mathrm{~h}$ dark) and incubated for 20 days to achieve the development of the fungus on leaves, facilitating the growth of separate fungal colonies used for the differential test.

Differential clones. The poplar material used for determination of the pathotypes of the Melampsora sp. present in Chile was $P$. $\times$ euroamericana 'Robusta', all virulences. To determine the virulence 1,2 , $3,4,5,6,7$, and 8 the following poplars were used: $P$. $\times$ euroamericana 'Ogy', $P . \times$ candicans 'Candicans o Aurora', $P . \times$ euroamericana 'Brabantica', $P . \times$ interamericana 'Unal', $P . \times$ interamericana 'Rap', P. deltoides '87B12', $P . \times$ interamericana 'Beaupré', and $P . \times$ interamericana 'Hoogvorts', respectively (Barrès et al. 2008; Pinon and Frey 2005). These clones were selected to discriminate poplar leaf rust and are widely used to determine pathotypes of $M$. laricipopulina in Europe (Pinon and Frey 2005). The Poplar Research Technology Center of the University of Talca introduced these poplar clones to Chile in 2003.

Growth conditions. The hybrids used were produced from 25cm-long cuttings previously disinfected with $30 \%$ hydrogen peroxide and established in pots containing a substrate combination of sand and pine bark compost (1:1) and planted in a greenhouse. Potted cuttings were placed in an insulated enclosure and were periodically watered and fertilized with a solution made of nitrogen, phosphorus, and potassium (ratio 1:2:2). The growth of the clones cultured under these conditions reached $120 \mathrm{~cm}$ in height after 6 months and showed complete foliar development.

Leaf disk bioassay. Poplar leaves were selected from the top of the plant according to the leaf plastochron index (LPI), considering the leaves between LPI5 and LPI8 (Coleman 1986), because these leaves are most susceptible to the pathogen (Sharma et al. 1980). Inoculation was conducted on foliar disks ( $2 \mathrm{~cm}$ in diameter). Each leaf disk was floated on a Petri dish containing distilled water with $2 \%$ agar, making sure that the lower part of the disk was upward, to facilitate the development of the fungus. A urediniospore suspension prepared at a concentration of $10^{4}$ urediniospores $/ \mathrm{ml}$ in distilled water with $1 \%$ agar was obtained from the leaves of $P . \times$ euroamericana 'Robusta' under laboratory conditions. From that urediniospore suspension, a $200-\mu 1$ aliquot was used to inoculate each poplar leaf disk of the differential clones. The inoculated poplar leaf discs were incubated under controlled conditions $\left(18 \pm 2{ }^{\circ} \mathrm{C}\right.$ and photoperiod of $16 \mathrm{~h}$ light $/ 8 \mathrm{~h}$ dark $)$.
Molecular characterization. DNA was extracted directly from urediniospores in pustules collected from leaves of $P$. trichocarpa $\times$ $P$. deltoides, $P$. deltoides $\times P$. nigra, $P$. trichocarpa $\times P$. nigra, and $P$. nigra in the different localities. The DNA extraction was performed using the Wizard Genomic DNA Purification Kit (Promega, Madison, WI). The ITS region ITS1-5.8S-ITS2 of the nuclear rDNA was amplified using primers ITS1 and ITS4 (White et al. 1990).

PCR was conducted in a My Gene series thermocycler (Peltier MG96G, LongGene Scientific Instruments, Hangzhou, P.R. China). Each PCR sample contained $10.0 \mu 1$ of Promega $5 \times$ colorless GoTaq Flexi Buffer, $0.4 \mu l$ of dNTP mix at $10 \mathrm{mM}$ (Thermo Fisher Scientific, Waltham, MA), $2.0 \mu \mathrm{l}$ of each primer at $0.5 \mathrm{mM}, 4.0 \mu \mathrm{l}$ of $\mathrm{MgCl}_{2}$ at $25 \mathrm{mM}, 27.4 \mu \mathrm{l}$ of ultrapure $\mathrm{H}_{2} \mathrm{O}, 0.26 \mu \mathrm{l}$ of GoTaq G2 DNA Polymerase $5 \mathrm{U} / \mu \mathrm{l}$ (Promega), and $4.0 \mu \mathrm{l}$ of template DNA in a final volume of $50 \mu \mathrm{l}$. A negative control without template DNA was always included. The thermocycling pattern was that described for the GoTaq G2 DNA Polymerase, considering the annealing temperature of $56^{\circ} \mathrm{C}$.

The PCR products were separated on $1 \%$ agarose gel electrophoresis immersed in tris-acetate-EDTA $1 \times$. PCR products were visualized on a 312-nm ECX-26.M ultraviolet transilluminator model. The PCR products were purified and sequenced by Macrogen (Geumcheon-gu, South Korea). The sequences were edited using ProSeq version 2.91 (University of Oxford, UK) and aligned using Clustal X 2.0 (Conway Institute, Dublin, Ireland). A BLAST search was performed against recognized sequences of Melampsora species in the GenBank (https://www.ncbi.nlm.nih.gov/) database. A total of seven isolates of $M$. larici-populina were deposited in GenBank with accession numbers MF788174 to MF788180. Leaf samples are preserved as dried voucher specimens and deposited into the Laboratorio de Sanidad Vegetal of University of Talca (codes M1ABVIIa, MIREVLLa, M1SP1Via, M2L0VIIb, M1LCVIIIa, M1CaVIa, and M4LQVIId).

Scanning electron microscope analysis. Fungal spores were analyzed using optical and scanning electron microscopy to determine the Melampsora species. The description and images of Spiers and Hopcroft (1988) and Newcombe and Chastagner (1993) were used for the identification of $M$. larici-populina. The rust spores were directly obtained from the leaves of poplars using carbon tape and placed under a low-voltage electron microscope LVEM5 (Delong Instruments, Brno-Medlánky, Czech Republic). To observe this type of spore, the electron microscope was adjusted to $5 \mathrm{~V}$, which allowed viewing of the spores without staining. The advantage of this type of microscopy is that the biological samples can be directly and rapidly observed (Drummy et al. 2004).

\section{Results}

The molecular characterization based on the sequencing on the intergenic region ITS1-5.8S-ITS2 of all our isolates resulted in 932-bp fragments, which a BLAST search in the GenBank database confirmed were $100 \%$ identical to sequences of M. larici-populina (GenBank reference JQ912668; Ihrmark et al. 2012).

Figure 1A shows an electronic microscope image of oval and ovate urediniospores with sizes ranging from 26 to $47 \mu \mathrm{m}$ in length and 13 to $16 \mu \mathrm{m}$ in width. The urediniospores were echinulate on their entire surface, except at one apical smooth patch (Fig. 1B). The observed urediniospores were ovate with a rounded apex and

Table 1. Virulences of Melampsora larici-populina isolates obtained from poplar plantations and isolated trees in the Central Valley of Chile

\begin{tabular}{llccll}
\hline Region & Location & Geographic coordinates & Analyzed samples, $\boldsymbol{N = 2 2 9}$ & Virulences & Virulences found (\%) \\
\hline O'Higgins & Coinco & $34^{\circ} 14^{\prime} \mathrm{S}, 74^{\circ} 54^{\prime} \mathrm{W}$ & 36 & 4 & 100 \\
Del Maule & Talca & $35^{\circ} 24^{\prime} \mathrm{S}, 71^{\circ} 38^{\prime} \mathrm{W}$ & 40 & 4,5 & 94,67 \\
Del Maule & Parral & $36^{\circ} 17^{\prime} \mathrm{S}, 71^{\circ} 16^{\prime} \mathrm{W}$ & 15 & $1,2,3,4,5$ & $50,33,77,88,77$ \\
Biobio & Cabrero & $37^{\circ} 0.1^{\prime} \mathrm{S}, 72^{\circ} 14^{\prime} \mathrm{W}$ & 20 & $2,4,5$ & $100,100,94$ \\
Biobio & Yumbel & $37^{\circ} 13^{\prime} \mathrm{S}, 72^{\circ} 25^{\prime} \mathrm{W}$ & 40 & 4 & 100 \\
Biobio & Los Ángeles & $37^{\circ} 30^{\prime} \mathrm{S}, 72^{\circ} 22^{\prime} \mathrm{W}$ & 20 & $4,5,6$ & $72,44,72$ \\
Araucanía & Temuco & $38^{\circ} 39^{\prime} \mathrm{S}, 72^{\circ} 27^{\prime} \mathrm{W}:$ & 10 & 4 & 100 \\
Araucanía & Traiguén & $38^{\circ} 12^{\prime} \mathrm{S}, 72^{\circ} 42^{\prime} \mathrm{W}$ & 18 & $4,5,6$ & $77,50,56$ \\
Los Ríos & Valdivia & $37^{\circ} 46^{\prime} \mathrm{S}, 72^{\circ} 0.5^{\prime} \mathrm{W}$ & 30 & 4,5 & 56,44 \\
\hline
\end{tabular}


a truncate, yellow hyaline wall. Observation of urediniospores under the optical microscope revealed thicker walls at the equatorial zone.

The analysis of the poplar leaf rust samples collected from different study locations and analyzed by pathotyping on differential poplar clones revealed the presence of six out of eight known virulences of M. larici-populina (Table 1). Virulence 4 was detected at all locations, but its combination with other virulences of the pathogen varied at each site. In Coinco, Yumbel, and Temuco, $100 \%$ of the samples exhibited only virulence 4 . In Talca and Valdivia, virulence 4 was associated with virulence 5 . Virulences 1 and 3 were found only in Parral. Virulence 2 was found in Cabrero (100\% of the samples) and in Parral (77\% of the samples). In Los Ángeles and Traiguén, all samples exhibited virulences 4,5 , and 6 .

\section{Discussion}

Several researchers have identified M. larici-populina using DNA analysis (Cervera et al. 1996; Xhaard et al. 2009). Various microsatellites have proven to be useful in characterizing the genetic structure of populations of $M$. larici-populina (Barrès et al. 2008). In the present study, all samples tested by PCR correspond to $M$. laricipopulina. In addition, we characterized the virulences of $M$. laricipopulina present in Chile. Morphological features of urediniospores and inoculation of poplar leaf rust samples collected from different locations and a differential set of poplar clones revealed the presence of virulences 1 to 6 of M. larici-populina. Scanning electron microscopy observations of urediniospores showed that they were echinulate on their entire surface, except for an apical smooth patch, a morphological feature typical of $M$. larici-populina (Newcombe and Chastagner 1993; Spiers and Hopcroft 1988). Furthermore, light microscopy analysis of urediniospores showed an equatorial wall thickening, consistent with the descriptions of M. larici-populina as reported by Newcombe and Chastagner (1993).

Another common rust affecting poplars, but not in Chile, according to the Agricultural and Animal Service (SAG 2004), is M. medusae Thümen f. sp. deltoidae, which has been identified in Brazil (FAO 2007) and Argentina (Steimel et al. 2005). This fungus develops on poplar leaves similar to $M$. larici-populina, but their morphologies are different. Urediniospores of M. medusae f. sp. deltoidae are evenly echinulate, except for an equatorial smooth patch, and do not show an equatorial wall thickening like M. laricipopulina (Spiers and Hopcroft 1988). All of the spores analyzed in the present study, derived from single poplar trees and plantations from different geographic areas of Chile, morphologically corresponded to $M$. larici-populina, thereby confirming the identity of the causal agent of poplar rust in Chile.

Strains developed on the cultivar Brabantica suggest the presence of virulence 3 . The differential cultivar Ogy was also infected, implying the presence of virulence 1 (Pinon and Frey 2005). The development of the fungus on the cultivar Aurora indicated the presence of virulence 2, as previously described by Krzan (1982). In addition, the results of the present study showed the development of some fungal strains on clones Unal, 87B12, and Rap, indicating the presence of virulences 4,5 , and 6 , respectively, consistent with the description of Pinon and Frey (2005).

The results of this study also showed that the presence of virulence differed depending on the site; however, the most frequent was virulence 4 . There are several hypotheses about the origin of the pathogenicity variability in M. larici-populina populations collected in Chile. New rust pathotypes could be transported with hybrid poplars imported into Chile, or the urediniospores are introduced by continental air currents. Several authors have proposed that spores can move from one continent to another and remain viable (Barrès et al. 2008; Nagarajan and Singh 1990; Wilkinson and Spiers 1976). However, further molecular studies are needed to verify these hypotheses in Chile.

Other causes might be related to the possibility that $M$. laricipopulina has succeeded in developing the sexual part of its life cycle (Pinon and Frey 2005). This scenario could be true if the main telial hosts such as Larix spp., $P$. ponderosa, and $P$. contorta were present in the localities under study (Newcombe et al. 1994). Newcombe and Chastagner (1993) reported that $P$. radiata is a telial host for
M. larici-populina in North America. However, in Chile, despite the wide distribution and abundance of $P$. radiata, there is no evidence that this species hosted this fungus. Further studies are needed to find other alternative hosts of $M$. larici-populina. Other causes of the changes in the virulence of the poplar leaf rust could be that the fungus developed the sexual phase of the cycle on new hosts (other conifers), as other Melampsora species do (Pei and Shang 2005).

Our results show that rust strains collected in different parts of Chile correspond to $M$. larici-populina, without evidence of the presence of other rusts, such as M. medusae or M. allii-populina. The analyses of $M$. larici-populina samples in different localities indicate the presence of virulences $1,2,3,4,5$, and 6 . Inoculation of poplar rust samples onto the differential set of clones showed no evidence of other virulences, such as virulences 7 or 8 . These results suggest the presence of variation within poplar leaf rust pathotypes in Chile, and the present study is the first to confirm the identities of the virulences developed by M. larici-populina in this country.
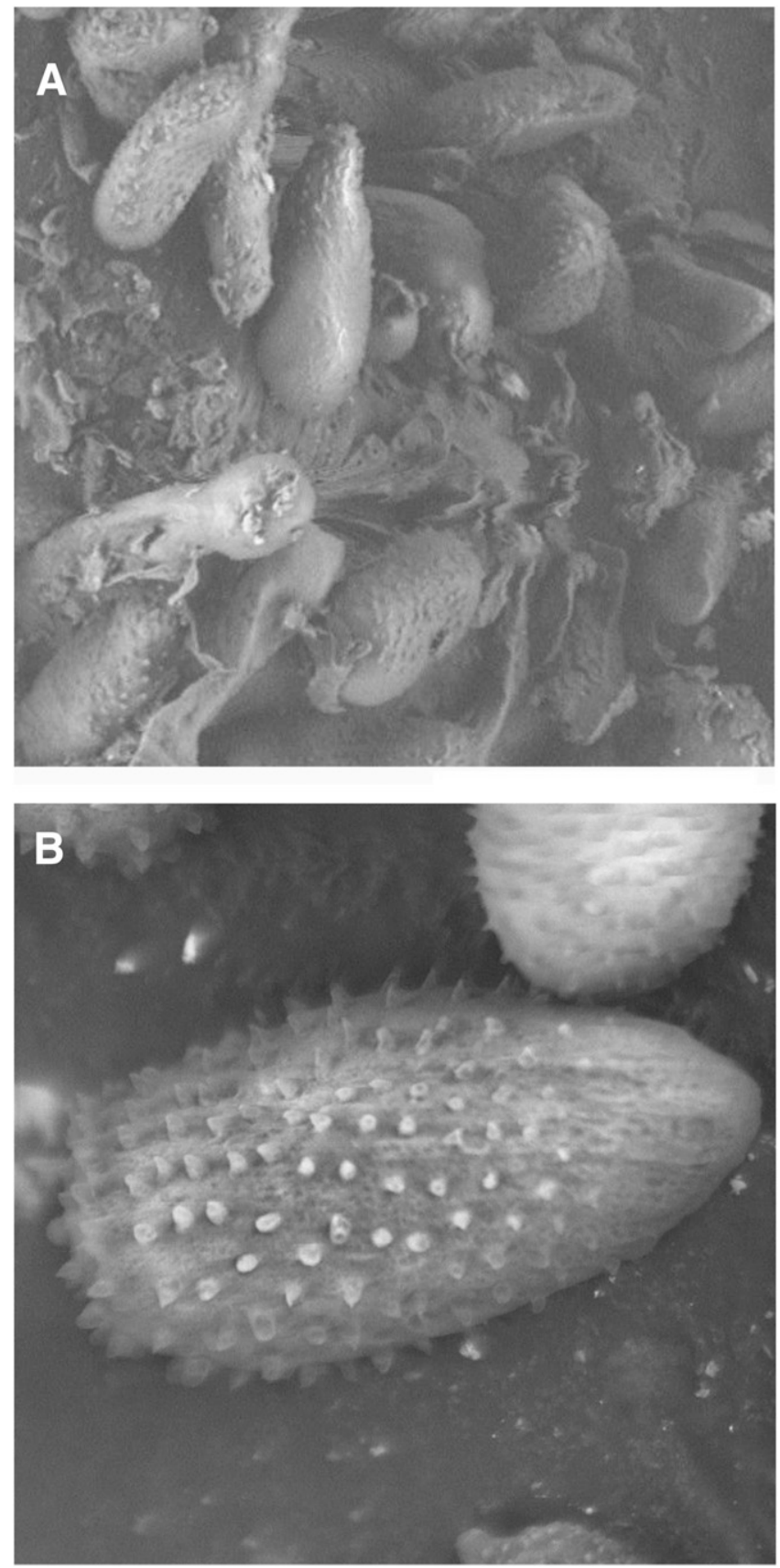

Fig. 1. A, Urediniospores of Melampsora larici-populina developed on its telial host, poplar. B, Magnification of rust urediniospores with echinulations on the entire surface except at one apical smooth patch, typical of M. larici-populina. 


\section{Acknowledgments}

The authors thank the Center for Bioinformatics and Molecular Simulation (CBSM) for the use of the electron microscope, the Poplar Research Technology Center, Plant Health Laboratory of the University of Talca, Greenwood Resources Chile S.A. for providing some of the poplar hybrids used in the present study, and Charles Abramson for valuable assistance with the manuscript. Moreover, the authors thank the Universidad de Talca for the PhD grant. Part of this manuscript was presented at the XVII Chilean Congress of Phytopathology.

\section{Literature Cited}

Barrès, B., Dutech, C., Andrieux, A., Halkett, F., and Frey, P. 2012. Exploring the role of asexual multiplication in poplar rust epidemics: Impact on diversity and genetic structure. Mol. Ecol. 21:4996-5008.

Barrès, B., Halkett, F., Dutech, C., Andrieux, A., Pinon, J., and Frey, P. 2008. Genetic structure of the poplar rust fungus Melampsora larici-populina: Evidence for isolation by distance in Europe and recent founder effects overseas. Infect. Genet. Evol. 8:577-587.

Cervera, M. T., Gusmao, J., Steenackers, M., Peleman, J., Storme, V., Vanden Brocck, A., Van Montagu, M., and Boerjan, W. 1996. Identification of AFLP molecular markers for resistance against Melampsora larici-populina in Populus. Theor. Appl. Genet. 93:733-737.

Coleman, J. 1986. Leaf development and leaf stress: Increased susceptibility associated with sink-source transition. Tree Physiol. 2:289-299.

Dowkiw, A., Husson, C., Frey, P., Pinon, J., and Bastien, C. 2003. Partial resistance to Melampsora larici-populina leaf rust in hybrid poplars: Genetic variability in inoculated excised leaf disk bioassay and relationship with complete resistance. Phytopathology 93:421-427.

Drummy, L. F., Yang, J., and Martin, D. 2004. Low-voltage electron microscopy of polymer and organic molecular thin films. Ultramicroscopy 99:247-256.

FAO. 2007. Overview of forest pests Brazil. Forest Health \& Biosecurity Working Papers. Working Paper FBS/11E. Forestry Department, Food and Agriculture Organization of the United Nations, Rome, Italy.

Fresa, R. 1936. Argentine Republic: Melampsora larici-populina in the Delta of Parana. Int. Bull. Plant Protec. 10:145-146.

Frey, P., Gèrard, P., Feau, N., Husson, C., and Pinon, J. 2005. Variability and population biology of Melampsora rusts on poplar. Pages 63-72 in: Rust Diseases of Willow and Poplar. M. H. Pei and A. R. McCracken, eds. CAB International, Wallingford, UK.

Gérard, P. R., Husson, C., Pinon, J., and Frey, P. 2006. Comparison of genetic and virulence diversity of Melampsora larici-populina populations on wild and cultivated poplar and influence of the alternate host. Phytopathology 96:1027-1036.

Hacquard, S., Petre, B., Frey, P., Hecker, A., Rouhier, N., and Duplessis, S. 2011. The poplar- poplar rust interaction: Insights from genomics and transcriptomics. J. Pathog. 2011:716041.

Husson, C., Ioos, R., Andrieux, A., and Frey, P. 2013. Development and use of new sensitive molecular tools for diagnosis and detection of Melampsora rust on cultivated poplar. For. Pathol. 43:1-11.

Ihrmark, K., Bödeker, I. T., Cruz-Martinez, K., Friberg, H., Kubartova, A., Schenck, J., Strid, Y., Stenlid, J., Brandström-Durling, M., Clemmensen, K. E., and Lindahl, B. D. 2012. New primers to amplify the fungal ITS2 region-Evaluation by 454-sequencing of artificial and natural communities. FEMS Microbiol. Ecol. 82:666-677.

Kern, F. D., and Thurston, H. W. 1954. Additional species of Uredinales from Colombia. Mycologia 46:354-357.

Krzan, Z. 1982. Poplar resistance to infection by the fungus Melampsora laricipopulina in field conditions. Arboretum Korn. 26:123-142.

Mujica, R. F., Vergara, C. C., and Oehrens, B. E. 1980. Flora Fungosa Chilena. Facultad de Agronomia, Universidad de Chile, Santiago, Chile.

Nagarajan, S., and Singh, D. V. 1990. Long-distance dispersion of rust pathogens. Annu. Rev. Phytopathol. 28:139-153.
Newcombe, G., and Chastagner, G. 1993. First report of the Eurasian poplar leaf rust fungus, Melampsora larici-populina, in North America. Plant Dis. 77: 532-535.

Newcombe, G., Chastagner, G. A., and McDonald, S. K. 1994. Additional coniferous aecial hosts of the poplar leaf rusts, Melampsora larici-populina and M. medusae f. sp. deltoidae. Plant Dis. 78:1218.

Pei, M. H., and Shang, Y. Z. 2005. A brief summary of Melampsora species on Populus. Pages 51-61 in: Rust Diseases of Willow and Poplar. M. H. Pei and A. R. McCracken, eds. CAB International, Wallingford, UK.

Pinon, J. 1992. Variability in the genus Populus in sensitivity to Melampsora rust. Silvae Genet. 41:25-44.

Pinon, J., and Frey, P. 1997. Structure of Melampsora larici-populina populations on wild and cultivated poplar. Eur. J. Plant Pathol. 103:159-173.

Pinon, J., and Frey, P. 2005. Interactions between poplar clones and Melampsora populations and their implications for breeding for durable resistance. Pages 139-154 in: Rust Diseases of Willow and Poplar. M. H. Pei and A. R. McCracken, eds. CAB International, Wallingford, UK.

Pinon, J., and Lefèvre, F. 1994. A new virulence found among isolates of Melampsora larici-populina. International Poplar Commission, Izmit, Turkey, 3-7 October.

Rubio-Meléndez, M., Zamudio, F., and Ramírez, C. 2011. Susceptibilidad de híbridos de Populus spp. al ataque de áfidos y roya en tres localidades de Chile. Bosque (Valdivia) 32:127-134.

Servicio Agrícola y Ganadero (SAG). 2004. Informe anual 2004. Subdepartamento de vigilancia y control de plagas forestales y exóticas invasoras. Ministerio de Agricultura. Servicio Agrícola y Ganadero, Santiago, Chile.

Sharma, J. K., Heather, W. A., and Winer, P. 1980. Effect of leaf maturity and shoot age of clones of Populus species on susceptibility to Melampsora laricipopulina. Phytopathology 70:548-554.

Spegazzini, C. 1918. Cuarta contribución a la micología chilena. Rev. Chil. Hist. Nat. 22:95-104.

Spiers, A., and Hopcroft, D. 1985. Ultrastructural studies of pathogenesis and uredinial development of Melampsora larici-populina and M. medusae on poplar and M. coleosporioides and M. epitea on willow. N. Z. J. Bot. 23: 117-133.

Spiers, A., and Hopcroft, D. 1988. Penetration and infection of poplar leaves by urediniospores of Melampsora larici-populina and Melampsora medusae. N. Z. J. Bot. 26:101-111.

Steenackers, M., Steenackers, V., and Delporte, T. 1994. A new race of Melampsora larici-populina in Belgium. International Poplar Commission, Izmit, Turkey.

Steimel, J., Chen, W., and Harrington, T. C. 2005. Development and characterization of microsatellite markers for the poplar rust fungi Melampsora medusae and Melampsora larici-populina. Mol. Ecol. Notes 5:484-486.

Vialle, A., Frey, P., Hambleton, S., Bernier, L., and Hamelin, R. 2011. Poplar rust systematics and refinement of Melampsora species delineation. Fungal Divers. 50:227-248.

White, T. J., Bruns, T., Lee, S., and Taylor, J. 1990. Amplification and direct sequencing of fungal ribosomal RNA genes for phylogenetics. Pages 315-322 in: PCR Protocols: A Guide to Methods and Applications. M. A. Innis, D. H. Gelfand, J. J. Sninsky, and T. J. White, eds. Academic Press, San Diego, CA.

Wilkinson, A. G., and Spiers, A. G. 1976. Introduction of poplar rusts Melampsora larici-populina and Melampsora medusae to New Zealand and their subsequent distribution. N. Z. J. Sci. 19:195-198.

Xhaard, C., Andrieux, A., Halkett, F., and Frey, P. 2009. Characterization of 41 microsatellite loci developed from the genome sequence of the poplar rust fungus, Melampsora larici-populina. Conserv. Genet. Resour. 1:21-25.

Zamudio, F., Yañez, M., Baettig, R., Guerra, F., and Espinoza, C. 2012. Review of the research conducted by the Poplar Technology Center in Chile: 1999-2011. For. Chron. 88:154-164. 